\title{
Modification of Irisin Level in Overweight/Obese Women during Pregnancy and Its Association with Some Metabolic Risk Factors
}

\author{
Mohammad Ahmad Hamza $^{1^{*}} \quad$ Yassar Yahya AL-Tamer ${ }^{2} \quad$ Omar Abdul Majeed AL-Habib
}

\begin{abstract}
${ }^{1}$ Assistant Lecturer, Department of Chemistry, Faculty of Science, University of Zakho, Kurdistan, Iraq, mohammad.hamza@uoz.edu.krd,009647703847794, ORCID: https://orcid.org/0000-0001-7935-9734.

${ }^{2}$ Formerly: Professor, Ninevah College of Medicine, Ninevah university, Mosul-Iraq, Currently: Visiting professor, Faculty of Science, University of Zakho, Kurdistan, Iraq medical laboratory techniques, AL-Noor University college, Mosul Iraq, yassar_altamer@yahoo.co.uk, ORCID: https://orcid.org/0000-0002-8200-566X .

${ }^{3}$ Professor, Department of Biology, College of science, International University of Erbil, Kurdistan, Iraq. And visiting professor, Faculty of Science, University of Zakho, Kurdistan Iraq, habbibomar@yahoo.com, ORCID: https://orcid.org/0000-0003-3947-4134.

*Corresponding author: mohammad.hamza@uoz.edu.krd,009647703847794
\end{abstract}

Received 25/7/2019, Accepted 14/1/2020, Published 8/9/2020

This work is licensed under a Creative Commons Attribution 4.0 International License.

\begin{abstract}
Irisin is a novel myokine and adipokine, its role during pregnancy and its association with some metabolic risk factors especially pre-pregnancy body mass index (pre-BMI) need more evaluation. The aim of the study is to find whether the pre-BMI could predict irisin levels during normal pregnancy and to clarify associations of irisin with some pathological parameters.

Irisin levels were estimated by ELISA in sera of 59 normal pregnant women who enrolled from December 2016 to May 2017 at Maternity Hospital, Zakho city, Kurdistan region (Iraq). Thirty-two normal-weight pregnant (pre-BMI $\leq 24.9 \mathrm{~kg} / \mathrm{m}^{2}$, Age $=24.03$ mean \pm 3.7 standard deviation) and 27 overweight/obese-pregnant (pre-BMI $>25 \mathrm{~kg} / \mathrm{m}^{2}$, Age $=27.6$ mean \pm 3.9 standard deviation) were accounted for each trimester as10: 8 in first trimester, 10:10 in second trimester and12:9 in third trimester respectively. Twenty-two healthy married non-pregnant women of reproductive age served as controls, accounted as 10 normal-weight women (BMI $\left.\leq 24.9 \mathrm{~kg} / \mathrm{m}^{2}\right)$ and 12 overweight/obese women (BMI>25 kg/m2).

In pregnant women as a whole, irisin level significantly increased compared to control $(\mathrm{p}=0.003)$, and correlated with the pre-BMI, FBS, TP and HOMA2-IR. Pre-BMI and TP predicted irisin levels in a whole study population $(\mathrm{p}=0.011$ and 0.014 respectively). In Overweight/Obese-pregnant, irisin increased significantly by $55.3 \%$ in first trimester compared with Overweight/Obese women control, then decreased progressively toward the end of gestation, correlated with TP, Albumin, FBS, HOMA2-IR and negatively correlated with gestational weight gained. TP and FBS independently predicted irisin level in Overweight/Obese-pregnant group.

Conclusion: Circulating irisin levels are influenced by pre-BMI, and both of TP and FBS predict irisin levels in overweight/obese pregnant. Irisin level should be a radical factor in future studies for pathological conditions linked to hypoproteinemias such as edema and hepatic disease.
\end{abstract}

Key words: HOMA2-IR, Irisin, Overweight/obese, Pre-BMI, Pregnancy

\section{Introduction}

The impact of elevating pre-pregnancy body mass index (pre-BMI) on maternal and fetal health became manifest through its association with various pathophysiological conditions, and even with the perinatal mortality specifically in the third trimester $(1,2)$. The adverse effect of obesity prior to pregnancy on pregnancy outcome is relating to the significant difference in metabolism between obese and normal-weight women during pregnancy $(3,4)$.

Irisin was first identified in 2012 as a myokine. It is released as the proteolytically cleaved product 
of fibronectin type III domain-containing protein 5 (FNDC-5) during acute exercise and during exposure to cold $(5,6)$. Irisin is capable of inducing a brown adipose pattern of gene expression in the white adipose tissue (WAT), increasing energy expenditure and thermogenesis (6). Different studies including patients and healthy individuals stated a positive correlation between irisin levels and BMI; suggesting irisin to be released also as an adipocytokine (7-9). In an animal study, the overexpression of FNDC-5 in obese mice caused a reduction in the size of subcutaneous adipose tissues (SAT), stimulated both lipolysis and intracellular lipid metabolism and suppressed lipid synthesis $(10,11)$.

In pregnancy, limited studies aimed to evaluate irisin level and its associations with the markers of metabolic syndromes (12-18). Ebert et al. revealed that irisin is positively correlated with pre-BMI, and its level is predicted by fasting insulin in a whole study population which involved normal pregnant and gestational diabetes mellitus (GDM) (13). In contrast, Piya and his co-workers found irisin level at the end term of gestation to be negatively correlated with 12 week gestation BMI and positively correlated with glucose, insulin, HOMA-IR, and lipids. Also, they found significant decrease in non-obese pregnant compared to obese and GDM pregnant after adjusting for the BMI (14). In contrast, a negative association between irisin and HOMA-IR in pregnancy was found by others (16). Clearly, additional works are needed to clarify these discrepancies. In addition, there is no study till now confirmed the association of irisin with Hypoproteinemia which occurs in lean and obese women during normal pregnancy specifically in developing countries $(19,20)$.

The effect of pre-BMI on irisin levels during pregnancy and associations of irisin with some metabolic risk factors were contradicted. The current study aims to answer the following question: does the pre-BMI predict irisin circulating levels during pregnancy? It also aimed to find the possible associations between irisin and the metabolic parameters such as FBS, insulin, HOMA-IR, total protein and lipids.

\section{Materials and Methods}

Subjects: In this cross-sectional study, for each trimester, thirty pregnant women with fasting blood sugar (FBS) less than $95 \mathrm{mg} / \mathrm{dL}$ (according to the diagnostic criteria of hyperglycemia, Word Health Organization WHO 2013) were equivalently enrolled as overweight/ obese pregnant women (pre-BMI > $25 \mathrm{~kg} / \mathrm{m} 2$ ) and normal weight pregnant women (pre-BMI $\leq 24.9$ $\mathrm{kg} / \mathrm{m} 2$ ). All women underwent a questionnaire, and clinical check carried out by medical staff in the Maternity Hospital of Zakho city between the first of December 2016 and the thirtieth of May 2017. The questionnaire included medical history, lifestyle, number of previous deliveries, gestational weeks, medications, height, pre-gravid weight(women who knew their weight before pregnancy were enrolled) and weight during pregnancy. Women with a history and/or family history of diabetes, GDM, thyroid dysfunction, kidney disease, dyslipidemia, preeclampsia, multiple pregnancy were excluded. After excluding cases which did not meet the criteria of the study, the total number of participants was reduced to 59. This number involved 32 normal weight pregnant women (Age $=24.03$ mean \pm 3.79 standard deviation) and 27 overweight/ obese pregnant women $(\mathrm{Age}=27.6$ mean \pm 3.94 standard deviation). Both normal weight pregnant women and overweight/ obese pregnant women were accounted in three trimester as10: 8 in first trimester (FT), 10:10 in second trimester (ST) and12:9 in third trimester (TT) respectively.

The control groups were chosen from female employees in the same hospital who volunteered in this study as twenty-two non-pregnant women. All of them were married at reproductive age, and they were subjected to the restrictions of the study including normal FBS. The control groups were selected according to the BMI to be 10 normal weight non-pregnant women control and 12 overweight/obese non-pregnant women control. The sample size for this study was calculated with $80 \%$ power at a $5 \%$ level of statistical significance. Our study was in agreement with the guidelines of Ethics Committee of the Maternity Hospital of Zakho city consistent with IEC number 384 in $20^{\text {th }}$ of November 2016. All women involved in this study had been informed about the nature and purpose of this work and written consents were obtained.

\section{Samples:}

Blood samples $(5 \mathrm{ml})$ were drawn from all subjects after 12 hours overnight fasting and allowed to clot for 30 minutes at room temperature; sera were separated and directly stored at $-70 \mathrm{C}^{\circ}$ after dividing each serum into several aliquots until they were used. The body mass index was calculated as weight $/$ height $^{2}$. Insulin resistance was assessed by Homeostatic Model Assessment of Insulin Resistance HOMA2IR which was calculated using HOMA2 Computer Model (https://www.dtu.ox.ac.uk/homacalculato) 
that was released by the Diabetes Trials Unit, University of Oxford: HOMA Calculator.

\section{Quantitative Measurements:}

Serum irisin level was estimated using competitive ELISA (Aviscera Bioscience, Santa Clara, CA, USA, cataloge No.SK00170-01). This kit has been shown to accurately quantify the recombinant and natural irisin. Fasting serum insulin was estimated using sandwich ELISA (Bioactive diagnostic, Germany, catalog No. BDIN31-BA). Fasting blood sugar, Serum Total cholesterol (TC), triglyceride (TG), high-density lipoprotein cholesterol (HDLC), Total protein (TP) and Albumin were estimated by the automatic analyzer Biolis 24i Premium which uses CORMAY kits. Very Low-Density Lipoprotein cholesterol (VLDL) concentration was estimated according to the following equation: VLDL (mg/ dl) =Triglyceride/5. Low-Density Lipoprotein cholesterol (LDL-C) was calculated mathematically by the following Friedewald's formula (Friedewald et al. 1972): LDL $(\mathrm{mg} / \mathrm{dl})=$ TC- (HDL + VLDL)

Globulin level was estimated mathematically by subtracting albumin from total protein (Burtis et al. 2008): Globulin concentration $(\mathrm{g} / \mathrm{dl})=$ Total protein $(\mathrm{g} / \mathrm{dl})-$ Albumin $(\mathrm{g} / \mathrm{dl})$

\section{Statistical Analysis:}

The statistical package for social science (SPSS)( IBM SPSS Statistics, version 25) was used for data analysis. Normal distribution data was assessed by Shapiro-Wilk's test, and the homogeneity of variances was assessed by Levene's test. One- way analysis of variance (ANOVA), Welch test (for normally distributed data) Kruskal-Wallis's test (for abnormally distributed data) were performed for multiple comparisons as well as Tukey HSD's test, James Howell's test to find the position of significance. Independent t-test (for normally distributed data) and Mann-Whitney test (for nonnormally distributed data) were used for comparisons between the pregnant groups and their control groups. Data were expressed as the mean \pm standard deviation (SD). Bivariate Person/Spearman correlation analyses and Automatic multiple linear regression analysis were performed to find possible associations between irisin and other parameters and to identify independent relationship. Non-normally distributed parameters were automatically transferred. $\mathrm{P}$ value $<0.05$ was considered statistically significant.

\section{Results: \\ Characteristics of Pregnant and Non-pregnant Women}

The clinical characteristics of 59 Pregnant and 22 non-pregnant are shown in Table 1. ANOVA test showed there is no significant difference in the pre-BMI within pregnant women groups to the BMI of non-pregnant group. This will ensure fair comparisons of irisin levels in normal pregnancy and control. Independent t-test showed significant increase in irisin level in pregnant women compared to non-pregnant $(\mathrm{p}=0.003)$. Welch test showed a significant difference between groups $(\mathrm{p}=0.016)$, and James Howell's test showed that the significant increase was in FT compared to non-pregnant women group ( $\mathrm{p}=0.031$ ).

Bivariate Correlation Analysis and Multivariate Linear Regression Analysis of Irisin in Pregnant Women

Bivariate Person and Spearman correlation analyses were performed as shown in Table 2 . Irisin was positively correlated with the pre-BMI, FBS, HOMA2-IR and TP ( $\mathrm{p}=0.026,0.02,0.06$ and 0.032 respectively). No correlation was found between irisin level and other metabolic parameters. To verify independent associations, forward-stepwise automatic multiple linear regression analysis was performed and revealed that both TP and pre-BMI predicted irisin level independent of FBS and HOMA2-IR ( $\mathrm{F}=6.362$, $\mathrm{P}=0.003$ ).

Characteristic of Normal Weight Pregnant Compared to Normal Weight Women Control

No significant increase was found between normal weight pregnant women as a whole and their control group, there is a $13.79 \%$ rise in normal weight pregnant women compared with control as shown in Table 3.

Bivariate Correlation Analysis of Normal Weight Pregnant Women

There is no correlation was found between irisin and other metabolic parameters except its positive correlation with number of delivery $(r=0.442$, $\mathrm{p}=0.011$ ).

Characteristic of Overweight/Obese Pregnant Women Compared to Overweight/Obese Women Control

T-test showed that irisin increase significantly in overweight/obese pregnant women as a whole compared with their control group $(\mathrm{p}=0.009)$ as shown in Table 3. James Howell's test following Welch test showed that irisin level was significantly higher in FT compared with control $(\mathrm{FT}=684.6$ mean $\pm 197 \mathrm{SD} ; \mathrm{ST}=561.9$ mean \pm 167 $\mathrm{SD} ; \mathrm{TT}=458.4$ mean $\pm 188.4 \mathrm{SD}$ and control= 440.7 mean $\pm 78.8 \mathrm{SD})$. 
Table 1 Characteristics of Pregnant and non-pregnant women

\begin{tabular}{|c|c|c|c|c|c|c|c|}
\hline Variables & $\mathrm{FT}, \mathrm{n}=18$ & $\mathrm{ST}, \mathrm{n}=20$ & $\mathrm{TT}, \mathrm{n}=21$ & $\begin{array}{l}\text { non-pregnant } \\
\text { women , } n=22\end{array}$ & P1 & $\begin{array}{l}\text { pregnant } \\
\text { women, } n=59\end{array}$ & $\mathrm{P} 2$ \\
\hline Age (years) & $25.1 \pm 3.86$ & $25.8 \pm 4.09$ & $26.04 \pm 4.79$ & $28.4 \pm 5.03$ & ${ }^{\mathrm{a}} 0.106$ & $25.7 \pm 4.2$ & $\mathrm{~m} 0.015$ \\
\hline pre-BMI $\left(\mathrm{kg} / \mathrm{m}^{2}\right)$ & $25.09 \pm 4.5$ & $25.1 \pm 4.2$ & $24.9 \pm 3.7$ & $25.6 \pm 3.2 *$ & a 0.946 & $21.9 \pm 1.8$ & t 0.554 \\
\hline $\mathrm{BMI}\left(\mathrm{kg} / \mathrm{m}^{2}\right)$ & $25.4 \pm 4.5$ & $26.9 \pm 4.1$ & $29.6 \pm 3.6$ & -- & -- & -- & -- \\
\hline Gestational weeks & $9.4 \pm 2.8$ & $19.4 \pm 3.75$ & $35.6 \pm 3.6$ & -- & -- & -- & -- \\
\hline GWG (kg) & $0.88 \pm 0.29$ & $4.8 \pm 1.6$ & $12.1 \pm 1.3$ & -- & -- & -- & -- \\
\hline TG (mg/dL) & $106.2 \pm 34.1$ & $179.2 \pm 70.1$ & $223.6 \pm 72.7$ & $84.1 \pm 32.04$ & k 0.0001 & $172.7 \pm 78.09$ & m 0.0001 \\
\hline $\mathrm{TC}(\mathrm{mg} / \mathrm{dL})$ & $162 \pm 37.2$ & $199.6 \pm 33.4$ & $242.2 \pm 40.7$ & $160.95 \pm 24.3$ & a $1 * 10^{-11}$ & $203.3 \pm 49.25$ & $t 2 * 10^{-6}$ \\
\hline HDL-C (mg/dL) & $47.38 \pm 6.7$ & $54.0 \pm 8.7$ & $55.85 \pm 8.17$ & $45.0 \pm 9$ & a $8 * 10^{-5}$ & $53.87 \pm 9.3$ & t 0.001 \\
\hline LDL-C (mg/dL) & $94.1 \pm 32.3$ & $110.5 \pm 24.3$ & $141.6 \pm 29.9$ & $99.1 \pm 20.9$ & a $7 * 10^{-7}$ & $116.6 \pm 34.7$ & t 0.008 \\
\hline VLDL-C (mg/dL) & $21.25 \pm 6.8$ & $35.5 \pm 14.7$ & $44.7 \pm 14.5$ & $34.4 \pm 15.8$ & k 0.0001 & $29.8 \pm 12.02$ & m 0.0001 \\
\hline $\mathrm{TP}(\mathrm{g} / \mathrm{dL})$ & $7.04 \pm 0.49$ & $6.6 \pm 0.42$ & $6.57 \pm 0.44$ & $7.1 \pm 0.37$ & k 0.0001 & $6.73 \pm 0.49$ & m0.0001 \\
\hline Albumin (g/dL) & $4.67 \pm 0.56$ & $4.28 \pm 0.35$ & $4.04 \pm 0.31$ & $4.8 \pm 0.3$ & k 0.0001 & $4.3 \pm 0.486$ & t $1 * 10-5$ \\
\hline Globulin (g/dL) & $2.4 \pm 0.53$ & $2.3 \pm 0.21$ & $2.5 \pm 0.29$ & $2.3 \pm 0.33$ & k 0.106 & $2.4 \pm 0.36$ & $\mathrm{~m} 0.566$ \\
\hline Irisin $(\mathrm{ng} / \mathrm{mL})$ & $597.6 \pm 204$ & $523 \pm 138.1$ & $490 \pm 181.3$ & $443.6 \pm 84.5$ & w 0.016 & $534.0 \pm 178.2$ & t 0.003 \\
\hline Insulin $(\mu \mathrm{IU} / \mathrm{mL})$ & $6.59 \pm 1.0$ & $6.4 \pm 0.77$ & $6.4 \pm 1.6$ & $6.4 \pm 0.95$ & k 0.598 & $6.5 \pm 1.19$ & m 0.432 \\
\hline FBS (mg/dL) & $77.3 \pm 10.1$ & $74.4 \pm 10$ & $76.7 \pm 9.6$ & $77.5 \pm 8.5$ & a 0.731 & $76.1 \pm 9.86$ & t 0.548 \\
\hline HOMA2-IR & $0.82 \pm 0.14$ & $0.79 \pm 0.107$ & $0.8 \pm 0.21$ & $0.8 \pm 0.12$ & k 0.766 & $0.808 \pm 0.16$ & m 0.766 \\
\hline
\end{tabular}

pre, Pre-pregnancy; BMI, body mass index; GWG, gestational weight gained; TG, triglyceride; TC, total cholesterol; HDL-C, high density lipoprotein cholesterol; LDL-C, low density lipoprotein cholesterol; VLDL-C, very low density lipoprotein cholesterol; TP, total protein; FBS, fasting blood sugar; HOMA2-IR; homeostatic model assessment of insulin resistance; FT, $1^{\text {st }}$ trimester; ST, $2^{\text {nd }}$ trimester; TT, $3^{\text {rd }}$ trimester; n, sample size; ${ }^{a}$, one-way (ANOVA)test ; ${ }^{\text {w }}$, Welch test; ${ }^{k}$, Kruskal wallis test. ${ }^{\mathrm{t}}$, in-depended t-test and ${ }^{\mathrm{m}}$, Mann-Whitny ; p1, P-value within groups; p2,p-value between pregnant vs non-pregnant. $\mathrm{p}<0.05$ considered significant.

Table 2 Bivariate correlation analysis and Multivariate regression analysis of irisin in pregnant women

\begin{tabular}{|c|c|c|c|c|c|}
\hline \multirow[t]{2}{*}{ parameters } & \multicolumn{2}{|c|}{ correlation analysis } & \multicolumn{3}{|c|}{ Multiple linear regression analysis } \\
\hline & $\mathrm{r}$ & $\mathrm{p}$ & Coefficient & importance & $\mathrm{p}$ \\
\hline TG & ${ }^{\circledR}-0.12$ & 0.366 & & & \\
\hline Pre-BMI & ${ }^{\circledR} 0.289 *$ & 0.026 & 13.298 & 0.520 & 0.011* \\
\hline TC & ${ }^{\circledR}-0.147$ & 0.267 & & & \\
\hline LDL-C & ${ }^{\circledR}-0.194$ & 0.144 & & & \\
\hline HDL-C & ${ }^{\circledR} 0.008$ & 0.952 & & & \\
\hline VLDL-C & ${ }^{\mathrm{s}} 0.102$ & 0.443 & & & \\
\hline FBS & ${ }^{\circledR}{ }^{0.303}$ * & 0.02 & - & - & - \\
\hline HOMA2-IR & ${ }^{\mathrm{s}} 0.246 *$ & 0.06 & - & - & - \\
\hline Insulin & ${ }^{\mathrm{s}} 0.072$ & 0.587 & & & \\
\hline T.P & ${ }^{\mathrm{s}} 0.280 *$ & 0.032 & 115.86 & 0.48 & 0.014* \\
\hline Albumin & ${ }^{\circledR} 80.219$ & 0.096 & & & \\
\hline Globulin & ${ }^{\mathrm{s}} 0.144$ & 0.277 & & & \\
\hline number of deliveries & ${ }^{\mathrm{s}} 0.17$ & 0.198 & & & \\
\hline GWG & ${ }^{\mathrm{s}}-0.153$ & 0.294 & & & \\
\hline BMI & ${ }^{\circledR} 0.167$ & 0.207 & & & \\
\hline Age & ${ }^{\mathrm{s}} 0.205$ & 0.119 & & & \\
\hline
\end{tabular}

pre, Pre-pregnancy; BMI, body mass index; TG, triglyceride; TC, total cholesterol; HDL-C, high density lipoprotein cholesterol; LDL-C, low density lipoprotein cholesterol; VLDL-C, very low density lipoprotein cholesterol; TP, total protein; FBS, fasting blood sugar; HOMA2-IR; homeostatic model assessment of insulin resistance; GWG, gestational weight gained; s, Spearman correlation; ${ }^{\circledR}$, Person correlation. $\mathrm{p}<0.05$ considered significant. 
Table 3 Characteristic of overweight/ obese pregnant women and normal weight pregnant women and their controls

\begin{tabular}{|c|c|c|c|c|c|c|}
\hline Variables & $\begin{array}{c}\text { normal weight } \\
\text { pregnant, } \\
n=32\end{array}$ & $\begin{array}{l}\text { normal weight } \\
\text { women } \\
\text { control, } n=10\end{array}$ & $\mathrm{p} 1$ & $\begin{array}{c}\text { overweight/ } \\
\text { obese pregnant, } \\
n=27\end{array}$ & $\begin{array}{c}\text { overweight/ obese } \\
\text { women control, } \\
\mathrm{n}=12\end{array}$ & $\mathrm{p} 2$ \\
\hline Age (years) & $24.03 \pm 3.79$ & $26.2 \pm 5.05$ & ${ }^{\mathrm{m}} \mathrm{NS}$ & $27.6 \pm 3.9$ & $30.25 \pm 4.4$ & ${ }^{\mathrm{t}} \mathrm{NS}$ \\
\hline pre-BMI $\left(\mathrm{kg} / \mathrm{m}^{2}\right)$ & $21.9 \pm 1.8$ & $22.7 \pm 1.64$ & ${ }^{\mathrm{t}} \mathrm{NS}$ & $28.59 \pm 2.49$ & $28.09 \pm 2.1$ & ${ }^{\mathrm{m}} \mathrm{NS}$ \\
\hline $\mathrm{TG}(\mathrm{mg} / \mathrm{dL})$ & $150.2 \pm 58$ & $67 \pm 16.5$ & t $9 * 10^{-9}$ & $199.6 \pm 90.7$ & $98.5 \pm 35.3$ & $\mathrm{~m} 6 * 10^{-5}$ \\
\hline TC (mg/dL) & $197.09 \pm 43.9$ & $145.3 \pm 15.6$ & $2 * 10^{-6}$ & $210.7 \pm 54.8$ & $174 \pm 22.97$ & ${ }^{\mathrm{t}} 0.006$ \\
\hline HDL-C (mg/dL) & $53.87 \pm 9.3$ & $44.1 \pm 8.2$ & ${ }^{\mathrm{m}} 0.005$ & $51.22 \pm 7.7$ & $45.7 \pm 9.96$ & ${ }^{\mathrm{t}} \mathrm{NS}$ \\
\hline LDL-C (mg/dL) & $113.8 \pm 30.87$ & $87.8 \pm 16.7$ & ${ }^{\mathrm{t}} 0.015$ & $119.9 \pm 39.1$ & $108.5 \pm 19.8$ & ${ }^{\mathrm{t}} \mathrm{NS}$ \\
\hline VLDL-C (mg/dL) & $29.8 \pm 12.02$ & $13.4 \pm 3.3$ & $2 * 10^{-9}$ & $39.92 \pm 18.1$ & $19.7 \pm 7.05$ & $\mathrm{~m} 1 * 10^{-5}$ \\
\hline $\mathrm{TP}(\mathrm{g} / \mathrm{dL})$ & $6.73 \pm 0.5$ & $7.1 \pm 0.358$ & ${ }^{\mathrm{t}} 0.029$ & $6.74 \pm 0.514$ & $7.26 \pm 0.39$ & ${ }^{\mathrm{t}} 0.004$ \\
\hline Albumin (g/dL) & $4.29 \pm 0.53$ & $4.8 \pm 0.317$ & ${ }^{\mathrm{t}} 0.006$ & $4.389 \pm 0.45$ & $4.87 \pm 0.3$ & ${ }^{\mathrm{t}} 0.002$ \\
\hline Globulin (g/dL) & $2.4 \pm 0.43$ & $2.3 \pm 0.21$ & ${ }^{\mathrm{m}} \mathrm{NS}$ & $2.356 \pm 0.42$ & $2.39 \pm 0.41$ & ${ }^{\mathrm{t}} \mathrm{NS}$ \\
\hline Irisin $(\mathrm{ng} / \mathrm{mL})$ & $508.9 \pm 158.2$ & $447.2 \pm 95$ & ${ }^{\mathrm{t}} \mathrm{NS}$ & $563.7 \pm 198$ & $440.7 \pm 78.8$ & ${ }^{\mathrm{t}} 0.009 *$ \\
\hline Insulin $(\mu \mathrm{lU} / \mathrm{mL})$ & $6.3 \pm 0.61$ & $6.39 \pm 1.12$ & ${ }^{\mathrm{m}} \mathrm{NS}$ & $7.6 \pm 1.6$ & $6.46 \pm 0.83$ & ${ }^{\mathrm{m}} \mathrm{NS}$ \\
\hline FBS (mg/dL) & $73.4 \pm 7.04$ & $77.65 \pm 9.8$ & ${ }^{\mathrm{t}} \mathrm{NS}$ & $78.5 \pm 13.8$ & $77.5 \pm 7.78$ & ${ }^{\mathrm{m}} \mathrm{NS}$ \\
\hline HOMA2-IR & $0.776 \pm 0.08$ & $0.79 \pm 0.14$ & ${ }^{\mathrm{m}} \mathrm{NS}$ & $0.845 \pm 0.2$ & $0.8 \pm 0.12$ & ${ }^{\mathrm{m}} \mathrm{NS}$ \\
\hline
\end{tabular}

pre, Pre-pregnancy; BMI, body mass index; GWG, gestational weight gained; TG, triglyceride; TC, total cholesterol; HDL-C, high density lipoprotein cholesterol; LDL-C, low density lipoprotein cholesterol; VLDL-C, very low density lipoprotein cholesterol; TP, total protein; FBS, fasting blood sugar; HOMA2-IR; homeostatic model assessment of insulin resistance; FT, $1^{\text {st }}$ trimester; ST, $2^{\text {nd }}$ trimester; TT, $3^{\text {rd }}$ trimester; $\mathrm{n}$, sample size; ${ }^{\mathrm{t}}$, in-depended $\mathrm{t}$-test and ${ }^{\mathrm{m}}$, Mann-Whitny ; p1, P-value between normal weight pregnant women and their control; p2,p-value between overweight/ obese pregnant women and their control. $\mathrm{p}<0.05$ considered significant.

Table 4 Bivariate Correlation analysis and multivariate linear regression analysis of irisin in overweight/obese pregnant women

\begin{tabular}{|c|c|c|c|c|c|}
\hline \multirow[t]{2}{*}{ parameters } & \multicolumn{2}{|c|}{ correlation analysis } & \multicolumn{3}{|c|}{ multiple linear regression analysis } \\
\hline & $\mathrm{r}$ & $\mathrm{p}$ & coefficient & important & $\mathrm{p}$ \\
\hline TG & ${ }^{\mathrm{s}}-0.199$ & 0.32 & & & \\
\hline GWG & ${ }^{\circledR}-\mathbf{0 . 4 3 7} *$ & 0.023 & - & - & - \\
\hline no.of delivery & s -0.117 & 0.561 & & & \\
\hline $\mathrm{TC}$ & ${ }^{(8)}-0.271$ & 0.172 & & & \\
\hline HDL-C & ${ }^{\circledR}-0.154$ & 0.445 & & & \\
\hline LDL-C & ${ }^{\circledR}-0.287$ & 0.147 & & & \\
\hline VLDL-C & s-0.199 & 0.32 & & & \\
\hline $\mathrm{TP}$ & s $0.491 * *$ & 0.009 & 180.98 & 0.519 & $0.01 *$ \\
\hline Albumin & ${ }^{\circledR} 0.422 *$ & 0.028 & - & - & - \\
\hline Globulin & ${ }^{\circledR} 0.154$ & 0.443 & & & \\
\hline Insulin & s 0.098 & 0.627 & & & \\
\hline FBS & ${ }^{\circledR} 0_{0.453} *$ & 0.018 & 7.19 & 0.481 & $0.013 *$ \\
\hline HOMA2-IR & ${ }^{\mathrm{s}} 0.411 *$ & 0.033 & - & - & - \\
\hline
\end{tabular}

pre, Pre-pregnancy; BMI, body mass index; TG, triglyceride; TC, total cholesterol; HDL-C, high density lipoprotein cholesterol; LDL-C, low density lipoprotein cholesterol; VLDL-C, very low density lipoprotein cholesterol; TP, total protein; FBS, fasting blood sugar; HOMA2-IR; homeostatic model assessment of insulin resistance; GWG, gestational weight gained; r, correlation coefficient ;s, Spearman correlation; ${ }^{\circledR}$, Person correlation. $\mathrm{p}<0.05$ considered significant.

Bivariate Correlation Analysis and Multivariate Linear Regression Analysis of Irisin in Overweight/ Obese Pregnant Women

Person and Spearman correlation analyses showed that irisin was positively correlated with TP, Albumin, FBS and HOMA2-IR ( $\mathrm{p}=0.009$, $0.028,0.0018$ and 0.003 respectively) and negatively correlated with gestational weight gained $(\mathrm{GWG})(\mathrm{p}=0.003)$. To verify independent associations, forward-stepwise Automatic multiple linear regression analysis was performed and revealed that TP and FBS predicted irisin level independent of albumin, HOMA2-IR and GWG $(\mathrm{F}=8.04, \mathrm{P}=0.002)$ as shown in Table 4. 


\section{Discussion}

In animal studies, irisin improves energy consumption and enhances lipolysis leading to increase energy expenditure and thermogenesis, improves insulin sensitivity, reduces body weight and improves glucose tolerance $(10,21,22)$. As a result of these activities, irisin should play a vital role in adaptation during pregnancy, providing an indication of maternal and fetus health. In this study, irisin increased significantly in 59 normal pregnant women compared with non-pregnant control. In the same way, studies found an increase in irisin level during pregnancy $(12,13)$. In addition, and for the first time, our results showed that both pre-BMI and TP predicted irisin level independently of other metabolic parameters during pregnancy. Ebert $\mathrm{T}$ and his co-worker found that irisin level was predicted by insulin during pregnancy, which may be due to including GDM and normal pregnant cases (13). For further accurate analysis, we separate pregnant and control groups into overweight/obese and normal weight women. Irisin increased non significantly by 13.79 in normal weight pregnant women group compared to control. Irisin correlated with the number of deliveries, and this could point a question, is the number of the previous deliveries positively reflexed on maternal and fetal health? This needs to be proved by additional work. Detection of no correlations between irisin and metabolic parameters in normal weight pregnant women may sustain this idea. However, irisin level significantly elevated in overweight/ obese pregnant women compared to control group. Irisin correlated with FBS, HOMA2-IR, TP, albumin, and negatively with GWG in overweight/ obese pregnant women. We found that both TP and FBS predicted irisin level in overweight/ obese pregnant women independently of other parameters. The correlations of irisin in a whole pregnant population clearly appeared depending upon overweight/ obese pregnant women group. And the increase in irisin level in FT is also related to overweight/ obese pregnant women group. Furthermore, the negative correlation which was detected between irisin and GWG means decrease irisin level with the progression of pregnancy in overweight/ obese pregnant women. Piya MK et al. also found a negative correlation between irisin level and 12 week BMI at the end of the third trimester whereas, Ebert $\mathrm{T}$ etal. stated appositive correlation between irisin and the pre-BMI $(13,14)$. Here some literatures that compared the adaptation in metabolism between obese and normal-weight women in early pregnancy, supporting our results. The resting energy expenditure (REE) in lean women decreases while, obese women tend to raise their REE which is positively associated with irisin level $(23,24)$. A study stated a correlation between fat mass of women prior to pregnancy and the energy needed for pregnancy $(r=0.72)$. The similar association with irisin levels is expected (25). In the early pregnancy, the dominating anabolic processes in normal weight pregnant women suppress lipolysis while the dominating catabolic processes in obese pregnant women activate lipolysis, suggesting rising in irisin level in overweight/ obese pregnant women compared to normal weight pregnant women (26). Furthermore, the decrease in the cumulative fat index for obese pregnant women compared to lean pregnant women was observed during pregnancy (3). This gives an indication to decrease irisin progressively as pregnancy progresses in an attempt to reduce browning of WAT to save energy. Besides, high pre-BMI is probably enhancing the low grade inflammation which increases in the third trimester and serves as down-regulator of FNDC5 expression, as a result decrease irisin level in the third trimester of obese women (27).

Lean women stored fat in the first half of pregnancy to use it in the second half when the fetal requirements of energy increase; there is no pathological condition due to this conversion. But in obese women, lipolysis starts early and it is stimulated by irisin as promoter of lipolysis, result in high circulating fatty acids levels. If the irisin continues its elevation this may lead to a pathological increase in FBS with a condition of insulin resistance, and also irisin resistance may occur in late pregnancy $(12,28)$. In recently published work, with the same study's population, ANGPTL8 a hepatokine and adipokine found to be significantly increased in TT group of overweight/ obese pregnant women. ANGPTL8 inhibits lipoprotein lipase (LPL) activity and suppresses the conversion of triglyceride into the free fatty acids (FFAs) as another mechanism to decrease FFAs levels, causing significant increase in TG levels at TT in overweight/ obese pregnant women compared to normal weight pregnant women (29). In overweight/ obese pregnant women, there was gradually decline in irisin level in ST and TT. This decrease in irisin level and the rise in ANGPTL8 together may overcome the increase in FBS and reduce insulin resistance by decreasing FFAs levels. On the other hand, in type-2 diabetic mice, the subcutaneous perfusion of irisin reduces hepatic gluconeogenesis and increases glycogenesis, improves insulin sensitivity and glucose homeostasis but, this effect in human is still debated (30). However, irisin was correlated 
with FBS and HOMA2-IR similar to other studies which found a positive correlation between irisin and HOMA-IR in pregnancy $(12-14,17)$. Certain physiological changes take place during normal pregnancy, the decrease in Total protein and albumin level was seen during pregnancy especially in developing countries. Hormonal changes, hemodilution and increase fetal requirements of amino acids may take up a part of the responsibility $(19,20)$. Our result also showed decrease TP and Albumin with the progression of pregnancy. Total protein in addition to FBS predicted irisin level in overweight/obese pregnant women group; this highlights the probable implication of irisin in other pathological conditions related to hypoproteinemia that occur during pregnancy such as preterm labor, edema and hepatic diseases.

\section{Conclusion:}

Irisin serum levels are independently and positively predicted by Pre-BMI in normal pregnancy. Women who enter pregnancy with high BMI undergo an increase in their irisin levels significantly in the first trimester to increase energy expenditure, and then irisin levels gradually decrease toward the end of pregnancy due to the reduction in the mass of white adipose tissue, and to decrease circulating free fatty acids. In obese women only, irisin was correlated with TP, Albumin, FBS and HOMA2-IR. Both of TP and FBS predict irisin levels in obese pregnant. Irisin level should be a radical factor in future studies for pathological conditions linked to hypoproteinemia such as preterm labor, edema and hepatic disease.

\section{Acknowledgments:}

We appreciate all support provided by the University of Zakho and by the staff of the Maternity Hospital in Zakho city. Also, we would like to thank Mr. Hassan B. Abdulqader (English department/University of Zakho) for revising this study.

\section{Ethical Guidelines:}

This work was approved by the ethics committee of the Maternal Hospital in Zakho city and written informed consent was also obtained from participants prior to enrollment.

\section{Conflict of Interests:}

The authors declare that there is no conflict of interests regarding the publication of this article.

\section{Authors' declaration:}

- Conflicts of Interest: None.

- We hereby confirm that all the Figures and Tables in the manuscript are mine ours. Besides, the Figures and images, which are not mine ours, have been given the permission for re-publication attached with the manuscript.

- The author has signed an animal welfare statement.

- Ethical Clearance: The project was approved by the local ethical committee in University of Zakho.

\section{References:}

1. Stubert J, Reister F, Hartmann S, Janni W. The risks associated with obesity in pregnancy. Dtsch Aerzteblatt Online [Internet]. 2018 Apr 20 [cited 2019 Aug 21];115(16):276-83. Available from: http://www.ncbi.nlm.nih.gov/pubmed/29739495

2. Aune D, Saugstad OD, Henriksen T, Tonstad S. Maternal body mass index and the risk of fetal death, stillbirth, and infant death: A systematic review and meta-analysis. JAMA - J Am Med Assoc [Internet]. 2014;311(15):1536-46. Available from: https://www.ncbi.nlm.nih.gov/pubmed/24737366

3. Most J, Marlatt KL, Altazan AD, Redman LM. Advances in assessing body composition during pregnancy. In: European Journal of Clinical Nutrition [Internet]. 2018 [cited 2019 Aug 22]. p. 645-56. Available from: http://www.ncbi.nlm.nih.gov/pubmed/29748651

4. Tarasenko K V, Gromova AM, Pikul K V, Lysenko RB, Nesterenko LA. Pathogenesis of insulin resistance in pregnant women with obesity. Wiad Lek [Internet]. 2018 [cited 2019 Aug 21];71(4):801$6 . \quad$ Available from: http://www.ncbi.nlm.nih.gov/pubmed/30099414

5. Boström P, Wu J, Jedrychowski MP, Korde A, Ye L, Lo JC, et al. A PGC1- $\alpha$-dependent myokine that drives brown-fat-like development of white fat and thermogenesis. Nature [Internet]. 2012 Jan 11 [cited 2019 Aug 21];481(7382):463-8. Available from: http://www.ncbi.nlm.nih.gov/pubmed/22237023

6. Lee P, Linderman JD, Smith S, Brychta RJ, Wang J, Idelson C, et al. Irisin and FGF21 Are Cold-Induced Endocrine Activators of Brown Fat Function in Humans. Cell Metab [Internet]. 2014 Feb 4 [cited 2019 Aug 21];19(2):302-9. Available from: http://www.ncbi.nlm.nih.gov/pubmed/24506871

7. Li M, Yang M, Zhou X, Fang X, Hu W, Zhu W, et al. Elevated Circulating Levels of Irisin and the Effect of Metformin Treatment in Women With Polycystic Ovary Syndrome. J Clin Endocrinol Metab [Internet]. 2015 Apr [cited 2019 Aug 21];100(4):1485-93. Available from: http://www.ncbi.nlm.nih.gov/pubmed/25675380

8. Crujeiras AB, Pardo M, Arturo R-R, Santiago N-C, Zulet MA, Martínez JA, et al. Longitudinal variation of circulating irisin after an energy restrictioninduced weight loss and following weight regain in obese men and women. Am J Hum Biol [Internet]. 2014 Mar 4 [cited 2019 Aug 21];26(2):198-207. Available from: http://www.ncbi.nlm.nih.gov/pubmed/24375850

9. Crujeiras AB, Pardo M, Casanueva FF. Irisin: 'fat' or artefact. Clin Endocrinol (Oxf) [Internet]. 2015 Apr [cited 2019 Aug 21];82(4):467-74. Available from: 
http://www.ncbi.nlm.nih.gov/pubmed/25287317

10. Xiong X-Q, Chen D, Sun H-J, Ding L, Wang J-J, Chen Q, et al. FNDC5 overexpression and irisin ameliorate glucose/lipid metabolic derangements and enhance lipolysis in obesity. Biochim Biophys Acta - Mol Basis Dis [Internet]. 2015 Sep [cited 2019 Aug 21];1852(9):1867-75. Available from: http://www.ncbi.nlm.nih.gov/pubmed/26111885

11. Gao S, Li F, Li H, Huang Y, Liu Y, Chen Y. Effects and molecular mechanism of GSTIrisin on lipolysis and autocrine function in 3T3-L1 adipocytes. Eckel J, editor. PLoS One [Internet]. 2016 Jan 22 [cited 2019 Aug 21];11(1):e0147480. Available from: http://www.ncbi.nlm.nih.gov/pubmed/26799325

12. Garcés MF, Peralta JJ, Ruiz-Linares CE, Lozano AR, Poveda NE, Torres-Sierra AL, et al. Irisin levels during pregnancy and changes associated with the development of preeclampsia. J Clin Endocrinol Metab [Internet]. 2014 Jun 1 [cited 2019 Aug 21];99(6):2113-9. Available from: https://academic.oup.com/jcem/article/99/6/2113/25 37764

13.Ebert T, Stepan H, Schrey S, Kralisch S, Hindricks J, Hopf L, et al. Serum levels of irisin in gestational diabetes mellitus during pregnancy and after delivery. Cytokine [Internet]. 2014 Feb [cited 2019 Aug 21];65(2):153-8. Available from: http://www.ncbi.nlm.nih.gov/pubmed/24355429

14. Piya MK, Harte AL, Sivakumar K, Tripathi G, Voyias PD, James S, et al. The identification of irisin in human cerebrospinal fluid: Influence of adiposity, metabolic markers, and gestational diabetes. Am J Physiol - Endocrinol Metab [Internet]. 2014 Mar 1 [cited 2019 Aug 21];306(5):E512-8. Available from: http://www.ncbi.nlm.nih.gov/pubmed/24398403

15. Yuksel MA, Oncul M, Tuten A, Imamoglu M, Acikgoz AS, Kucur M, et al. Maternal serum and fetal cord blood irisin levels in gestational diabetes mellitus. Diabetes Res Clin Pract [Internet]. 2014 Apr [cited 2019 Aug 21];104(1):171-5. Available from:

http://www.ncbi.nlm.nih.gov/pubmed/24447809

16. Kuzmicki M, Telejko B, Lipinska D, Pliszka J, Szamatowicz M, Wilk J, et al. Serum irisin concentration in women with gestational diabetes [Internet]. Vol. 30, Gynecological Endocrinology. 2014 [cited 2019 Aug 21]. p. 636-9. Available from: http://www.ncbi.nlm.nih.gov/pubmed/24850254

17. Erol O, Erkal N, Ellidağ HY, İsenlik BS, Aydın Ö, Derbent $\mathrm{AU}$, et al. Irisin as an early marker for predicting gestational diabetes mellitus: a prospective study. J Matern Neonatal Med [Internet]. 2016 Nov 16 [cited 2019 Aug 21];29(22):3590-5. Available from: http://www.ncbi.nlm.nih.gov/pubmed/26782983

18.Usluoğullari B, Usluogullari CA, Balkan F, Orkmez M. Role of serum levels of irisin and oxidative stress markers in pregnant women with and without gestational diabetes. Gynecol Endocrinol [Internet]. 2017 May 4 [cited 2019 Aug 21];33(5):405-7. Available

from: http://www.ncbi.nlm.nih.gov/pubmed/28277125

19.Donangelo CM, Bezerra FF. Pregnancy: Metabolic Adaptations and Nutritional Requirements. In: Encyclopedia of Food and Health [Internet]. Elsevier; 2015 [cited 2019 Aug 21]. p. 484-90. Available from: https://linkinghub.elsevier.com/retrieve/pii/B978012 3849472005651

20. Sufrin S, Nessa A, Islam MT, Das RK, Rahman MH. Study on Serum Albumin in Third Trimester of Pregnancy. Mymensingh Med J [Internet]. 2015 Jul [cited 2019 Aug 21];24(3):464-6. Available from: http://www.ncbi.nlm.nih.gov/pubmed/26329940

21.Castillo-Quan JI. From white to brown fat through the PGC-1 $\alpha$-dependent myokine irisin: Implications for diabetes and obesity [Internet]. Vol. 5, DMM Disease Models and Mechanisms. 2012 [cited 2019 Aug 21]. p. 293-5. Available from: http://dmm.biologists.org/cgi/doi/10.1242/dmm.009 894

22.Roca-Rivada A, Castelao C, Senin LL, Landrove MO, Baltar J, Crujeiras AB, et al. FNDC5/Irisin Is Not Only a Myokine but Also an Adipokine. Luque RM, editor. PLoS One [Internet]. 2013 Apr 11 [cited 2019 Aug 21];8(4):e60563. Available from: http://www.ncbi.nlm.nih.gov/pubmed/23593248

23.Prentice AM, Goldberg GR, Davies HL, Murgatroyd PR, Scott W. Energy-sparing adaptations in human pregnancy assessed by whole-body calorimetry. Br J Nutr [Internet]. 1989 Jul [cited 2019 Aug 21];62(1):5-22. Available from: http://www.ncbi.nlm.nih.gov/pubmed/2789988

24. Huh JY, Panagiotou G, Mougios V, Brinkoetter M, Vamvini MT, Schneider BE, et al. FNDC5 and irisin in humans: I. Predictors of circulating concentrations in serum and plasma and II. mRNA expression and circulating concentrations in response to weight loss and exercise. Metabolism [Internet]. 2012 Dec [cited 2019 Aug 21];61(12):1725-38. Available from: http://www.ncbi.nlm.nih.gov/pubmed/23018146

25. Prentice AM, Spaaij CJ, Goldberg GR, Poppitt SD, van Raaij JM, Totton M, et al. Energy requirements of pregnant and lactating women. Eur J Clin Nutr [Internet]. 1996 Feb [cited 2019 Aug 21];50 Suppl 1:S82-110; discussion S10-1. Available from: http://www.ncbi.nlm.nih.gov/pubmed/8641268

26. Iva SK. Metabolic Adaptations in Pregnancy in Lean and Obese Women - A Literature Review. Res Obstet Gynecol. 2013;2(4):37-47.

27. Matsuo Y, Gleitsmann K, Mangner N, Werner S, Fischer T, Bowen TS, et al. Fibronectin type III domain containing 5 expression in skeletal muscle in chronic heart failure-relevance of inflammatory cytokines. J Cachexia Sarcopenia Muscle [Internet]. 2015 Mar [cited 2019 Aug 21];6(1):62-72. Available from: http://www.ncbi.nlm.nih.gov/pubmed/26136413

28.Chen X, Stein TP, Steer RA, Scholl TO. Individual free fatty acids have unique associations with inflammatory biomarkers, insulin resistance and insulin secretion in healthy and gestational diabetic pregnant women. BMJ Open Diabetes Res Care 
[Internet]. 2019 May 16 [cited 2019 Aug 21];7(1):e000632. Available from: http://drc.bmj.com/lookup/doi/10.1136/bmjdrc2018-000632

29.Hamza MA, Tamer YY AL, AL-Habib OAM. Variation in Circulating Betatrophin/ANGPTL8 Levels in Normal and Overweight/Obese Pregnant Women. J Clin DIAGNOSTIC Res [Internet]. 2019 [cited 2019 Aug 21]; Available from: https://jcdr.net/article_fulltext.asp?issn=0973-
$709 x \&$ year $=2019 \&$ volume $=13 \&$ issue $=8 \&$ page $=\mathrm{BC} 0$ 4\&issn=0973-709x\&id=13073

30.Liu TY, Shi CX, Gao R, Sun HJ, Xiong XQ, Ding L, et al. Irisin inhibits hepatic gluconeogenesis and increases glycogen synthesis via the PI3K/Akt pathway in type 2 diabetic mice and hepatocytes. Clin Sci [Internet]. 2015 Aug 19 [cited 2019 Aug 21];129(10):839-50. Available from: http://www.ncbi.nlm.nih.gov/pubmed/26201094.

\title{
تغير مستوى الايرسين في النساء زائدي الوزن/البلينات اثناء الحمل وعلاقته ببعض عوامل الخطوره الايضيه
}$$
\text { عمرعبد المجيا الحبيب } 3
$$

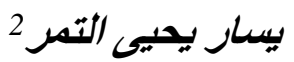

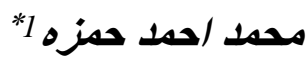

1 مدس مساعد , قسم الكيمياء ,كلية العلوم , جامعه زاخو ,اقليم كوردستان العر اق.

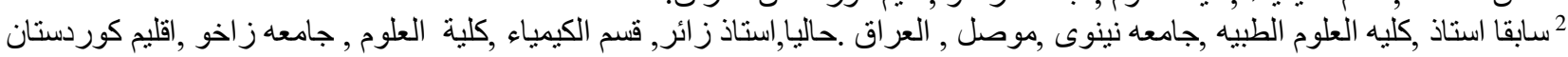

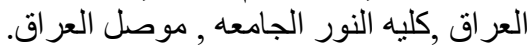
3 استاذ ,قسم علوم الحياه, كليه العلوم ,جامعه اربيل الدوليه ,كوردستان العر اق و استاذ زائر, كلية العلوم ,جامعهز زاخو ,كوردستان العراق.
\end{abstract}

الايرسين كبروتين حيوي يفرز من الانسجه العضليه والانسجه الدهنيه وضيفته اثناء الحمل وعلاقته ببعض عوامل الخطوره

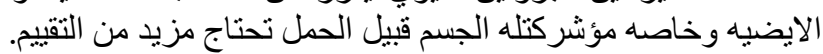
الهدف من الدراسه:هو معرفه امكانيه التتبؤ بمستوى الايرسين منين اثناء الحمل من خلال مؤشركتله الجسم قبيل الحمل وايضا توضيح ارتباط

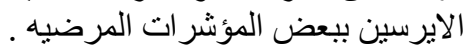

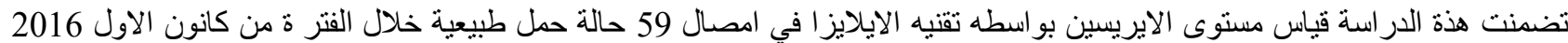

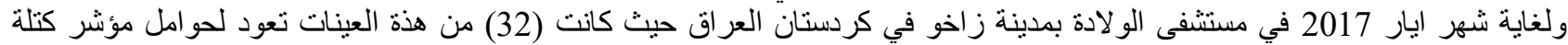

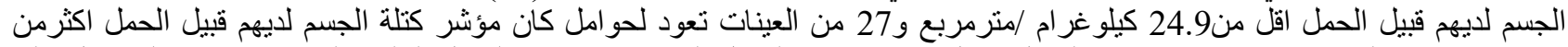

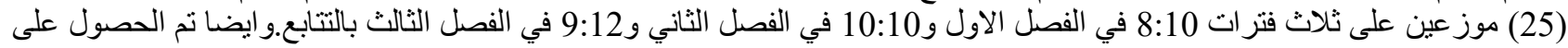

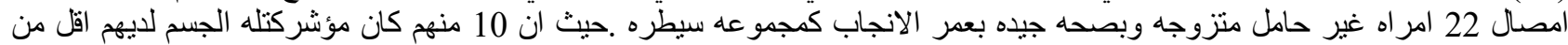

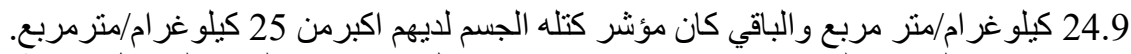

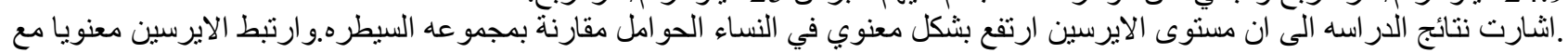

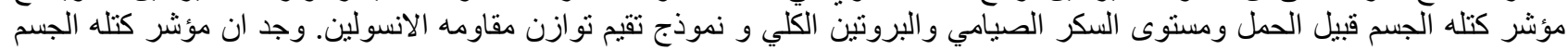

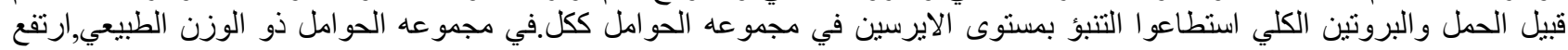

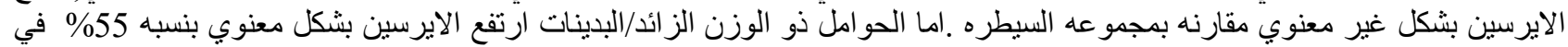

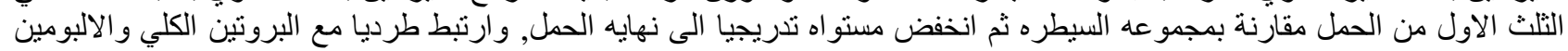

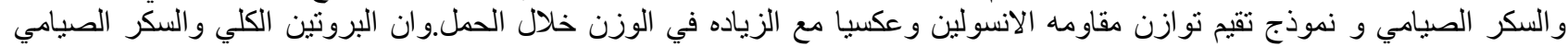

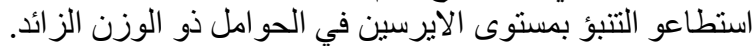

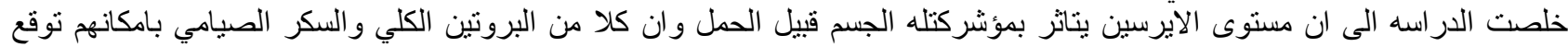

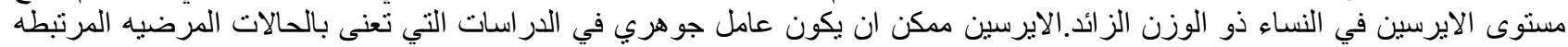

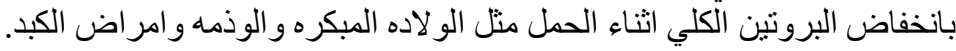

الكلمات المفتاحيه: نموذج تقيم تو ازن مقاومه الانسولين, الايرسين, الوزن الزائد/البدينات, مؤشر كتله الجسم قبيل الحمل, الحمل 